\title{
Correction: HDAC5, a potential therapeutic target and prognostic biomarker, promotes proliferation, invasion and migration in human breast cancer
}

\section{Anqi Li, Zebing Liu, Ming Li, Shuling Zhou, Yan Xu, Yaoxing Xiao, Wentao Yang}

Copyright: Li et al. This is an open-access article distributed under the terms of the Creative Commons Attribution License (CC-BY), which permits unrestricted use, distribution, and reproduction in any medium, provided the original author and source are credited.

Present: There is a duplication of images within Figure 5F and a typing error within Figure 4B.

Correct: The proper figure images are shown below. The authors sincerely apologize for this error..

Original article: Oncotarget. 2016; 7:37966-37978. doi: 10.18632/oncotarget.9274

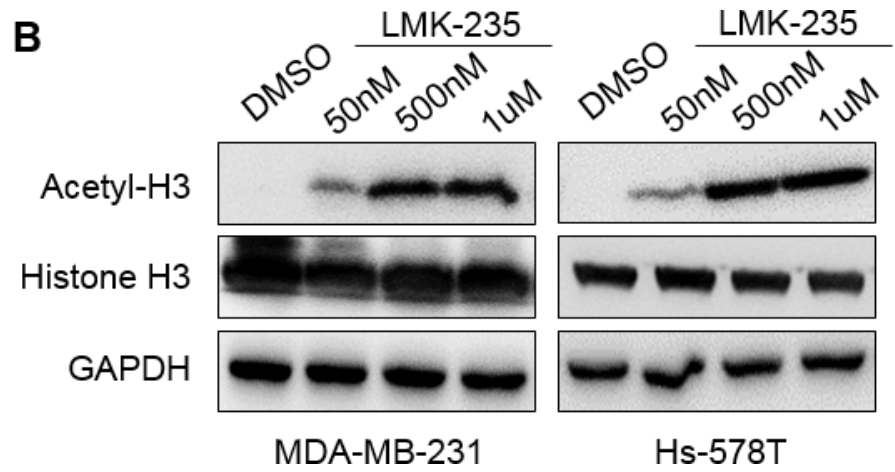

Figure 4: LMK-235 inhibits BC cell proliferation and induces apoptosis. B. MDA-MB-231 and Hs-578T cells were treated with DMSO or $50 \mathrm{nM}, 500 \mathrm{nM}$, or $1 \mu \mathrm{M}$ LMK-235 for 24 hours. The levels of acetyl-histone H3 and total histone H3 were examined by western blot. GAPDH was used as a loading control. 


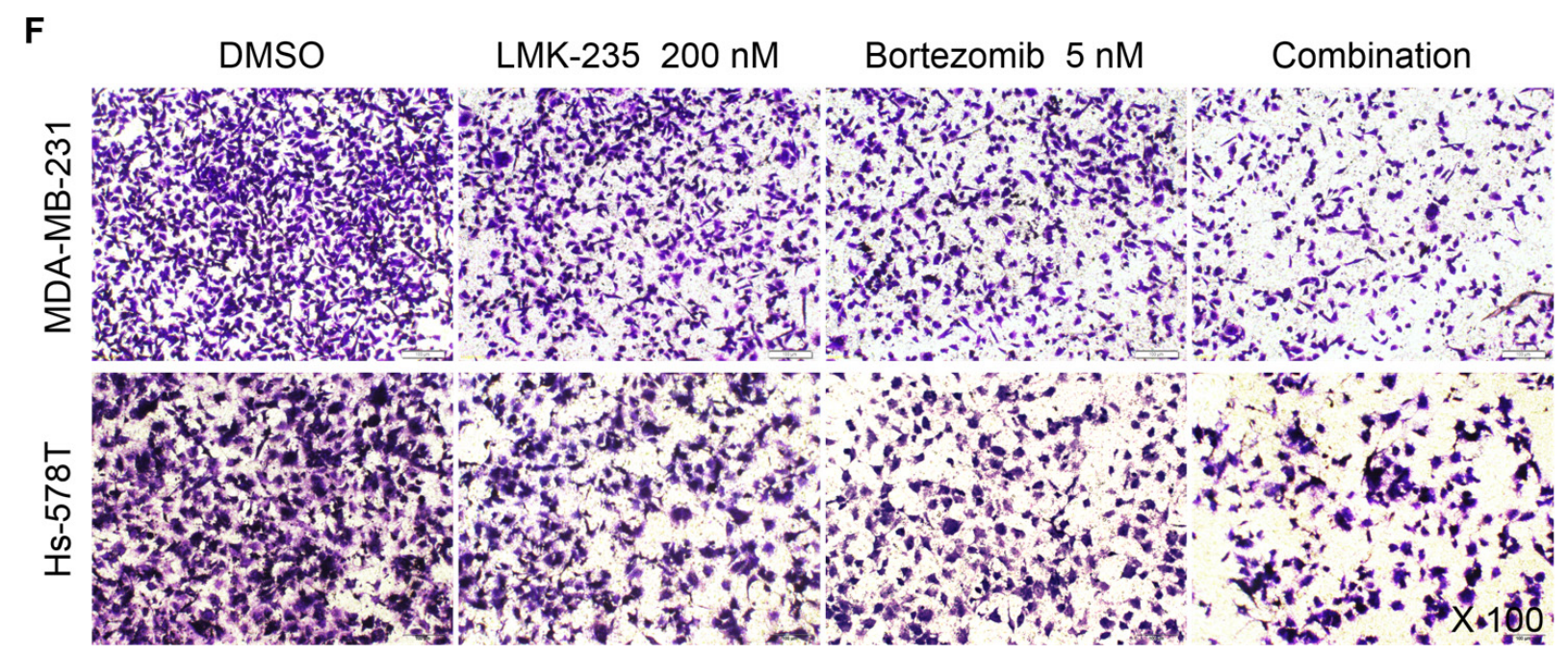

Figure 5: LMK-235 synergizes with bortezomib in BC cells. F. MDA-MB-231 and Hs-578T cells were plated in Matrigel invasion chambers and treated with $200 \mathrm{nM}$ LMK-235 and/or $5 \mathrm{nM}$ bortezomib for 24 hours. Three separate experiments were conducted, and representative results are shown. Magnification, $\times 100$. Columns indicate the average number of invading cells from 5 random microscopic fields. ${ }^{*}<0.05$ compared with the DMSO group; ${ }^{*} \mathrm{p}<0.05$ compared with the equivalent doses in the LMK-235- or bortezomib-treated groups. 